\title{
Apuntes para pensar las Meditaciones del Quijote de José Ortega y Gasset con el psicoanálisis
}

\author{
Cristina Múgica Rodríguez
}

Partiendo de un estudio sobre Ortega y Gasset y el psicoanálisis, este trabajo pretende apuntar vínculos entre las Meditaciones del Quijote y el pensamiento psicoanalítico y bordar en torno a la noción de amor intellectualis, a la dicotomía entre la latencia y la patencia, a la perspectiva y la construcción de la realidad, a la estética, el concepto y el sentido, a la cultura, a la novela realista y a las dimensiones trágicas y cómicas del héroe.

Palabras Clave: Ortega y Gasset, psicoanálisis, filosofía, obra cervantina.

Based on a book about Ortega y Gasset and pychoanalysis, these notes are intended as an exploration of Meditaciones del Quijote in relation to freudian and lacanian thought. The notions by Ortega considered in this paper are: amor intellectualis, latency and the manifest, perspective and construction of reality, aesthetics, the concept and the sense, culture, the realistic novel, and the tragic and comic aspects of heroism. 

Cristina Múgica Rodríguez

Instituto de Investigaciones Filológicas, UNAM

\section{Apuntes para pensar las Meditaciones del Quijote de José Ortega y Gasset con el psicoanálisis}

\section{Nota introductoria}

En su libro Ortega y el psicoanálisis (1997), Carlos Enrique García Lara trabaja sobre la relación con el pensamiento psicoanalítico de quien promoviera y prologara la primera traducción de las obras completas de Sigmund Freud al español. El presente trabajo es un intento por encontrar en las Meditaciones del Quijote vínculos con las teorías psicoanalíticas freudianas y lacanianas para pensar de otra manera lo que Ortega y Gasset elabora en relación con la importante obra cervantina.

A lo largo de mis lecturas, encuentro en las Meditaciones del Quijote (1914) diversos temas que, si bien se desprenden de y se conjugan en torno al Quijote, también se dispersan o disgregan; se agrupan y concatenan para reacomodarse de distintas maneras. De este modo, he partido de las consideraciones de Ortega relativas al objeto de las meditaciones, esto es, del Quijote como objeto estético, tal como aparecen en el prólogo "Lector...". Posteriormente, he intentado seguir en la "Meditación preliminar" la pregunta por el ser de las cosas, la dicotomía 
entre patencia y latencia; los planteamientos sobre la construcción de la realidad y la perspectiva, la alétheia o revelación, la contraposición entre experiencia de los sentidos y cultura, el arte mediterráneo, el concepto y el amor intellectualis. Finalmente, me asomo a las ideas sobre la novela realista y su carácter tragicómico, el héroe y la autenticidad presentes en la "Meditación primera".

Dado el carácter exploratorio de este trabajo, me he permitido anotar algunas resonancias que, desprendidas de mi principal objeto de estudio, remiten a la propia novela cervantina $y$, en ocasiones, a otros autores.

\section{Referencias a Freud en la obra de Ortega y Gasset}

Ortega y Gasset se refiere explícitamente a Freud en algunos trabajos. En el artículo "Psicoanálisis, ciencia problemática" (1911), cuestiona el carácter científico de la disciplina inaugurada por el psiquiatra vienés. De esta manera, ubicando el pensamiento freudiano en el terreno de la verosimilitud, afirma que estas doctrinas resultan, "más que falsas, no verdaderas, pero científicamente sugestivas" (Ortega y Gasset, "Psicoanálisis, ciencia problemática", 218). El filósofo agrega que las ideas de Freud plantean un tema de discusión psicológica o, mejor, lógica y que el vienés "se planta de un salto, si no en la metafísica, en los confines metafísicos de la psicología” (220). Advierte finalmente que el pensamiento freudiano carece de fórmulas matemáticas para establecer conexiones entre series de variaciones fenoménicas. Por otra parte, en este mismo trabajo, Ortega aborda brevemente algunos de los hallazgos de Freud en relación con los estudios sobre la histeria, la noción de expulsión o remoción (Verdrängung), lo inconsciente, el pensamiento por asociaciones, los lapsus, el síntoma y los recuerdos encubridores. 
En 1920, en el apartado "La psicología de cascabel" del ensayo El Quijote en la escuela, Ortega se refiere a las tesis del vienés en relación con los traumas de infancia y la presencia de ésta última en el psiquismo adulto; propone una pedagogía que eduque la vitalidad espontánea, "analizándola en sus componentes, hallando métodos para aumentarla, equilibrarla y corregir sus deformaciones", en vez de ejercer represión sobre la vida pulsional de los niños (Ortega y Gasset, El Quijote en la escuela, 301).

En 1922, Ortega y Gasset, en el "Prólogo" a las Obras completas de Freud, a propósito de la Interpretación de los sueños afirma:

Su libro sobre la vida de los sueños es una de las producciones más interesantes del pensamiento contemporáneo. En él desarrolla Freud la idea de que nuestra conciencia fabrica constantemente símbolos de la sexualidad, a la vez de una pureza sublime y de una inmaterialidad platónica (Ortega y Gasset, "Prólogo", 302).

Finalmente, en el artículo "Vitalidad, alma, espíritu" de 1924, Ortega establece una distancia radical con el psicoanálisis a partir de su concepción integral de la vida psíquica:

Creo que en el sistema de Freud hay algunas ideas útiles y claras: pero su conjunto me es poco afín. Para no hablar de cuestiones particulares, indicaré sólo que la psicología de Freud tiende a hacer de la vida psíquica un proceso mecánico, bien que de un mecanismo mental y no físico. Ahora bien: yo creo superada en principio por la ciencia actual esa propensión mecanicista, y me parece más fecunda una teoría psicológica que no atomiza la conciencia explicándola como mero resultado de asociaciones y disociaciones entre elementos sueltos (Ortega y Gasset, Vitalidad, alma y espíritu, 452).

Ahora bien, más allá de las referencias directas a Freud, García Lara lee a lo largo de su libro importantes coincidencias 
entre el filósofo y el fundador del psicoanálisis en cuanto a la división constitutiva del sujeto, al problema de la verdad en los terrenos epistémico, ontológico y ético y a la consideración del deseo como motor del psiquismo. Estas nociones aparecen en la obra del filósofo español en un nivel que pudiera identificarse como "latente", para tomar una noción del propio Ortega de la que hablaré adelante y que consiste en un nivel de "profundidad" o, siguiendo a Julián Marías, estructural. ${ }^{1}$

\section{El objeto de las Meditaciones}

Escritas en forma de ensayos (de exagium, acto de pesar algo, palabra emparentada con exigere y con examen), las Meditaciones consisten en una exploración que, más allá de las superficies de las cosas, se adentra en territorios donde se pierden asideros y apoyos. Meditar es, siguiendo el discurso del libro que me ocupa, abrir camino, en un esfuerzo "doloroso e integral”, con la tensión del ánimo. El objeto de las meditaciones de Ortega y Gasset es una novela a partir de la cual quiere preguntar por España, por la historia, por la realidad, por la verdad, por la interpretación, por la cultura, por la novela realista, por la condición subjetiva.

En el prólogo "Lector...", en contra de Miguel de Unamuno, Ortega hace un llamado a entender a Don Quijote como una "cosa artística", hecha de una "sustancia llamada estilo". En sus palabras:

cada objeto estético es individuación de un protoplasma-estilo. Así el individuo Don Quijote es un individuo de la especie de Cervantes (Ortega y Gasset, Meditaciones del Quijote, 87).

\footnotetext{
${ }^{1}$ Cfr. el prólogo de Jaime de Salas Ortueta al libro de García Lara, Ortega y el psicoanálisis.
} 
De esta manera, el filósofo señala que, lo que se trasluce, más allá del personaje, es el discurso de un escritor. Se trata de un quijotismo, sí, pero no del personaje, sino del propio Cervantes. "Y no el de Cervantes en los baños de Argel, no en su vida, sino en su libro" (87). En sus Ideas sobre la novela, Ortega dirá que la condición artística de dicho género radica en su estructura, esto es, de un organismo a partir del cual emana una forma (Ortega y Gasset, Ideas sobre la novela, 399).

En la sección dedicada al Quijote en España, sueño y verdad (1965), María Zambrano sintetiza la discusión que con Unamuno entabla Ortega como una en la que, al mito que construye el primero, contrapone el segundo la ambigüedad que implica la novela, con lo que se establece un dilema entre las "razones de amor" de las que habla Ortega (en las que se implica a veces la ironía) y la fe voluntariosa que defiende Unamuno:

¿Queremos ser lo uno o lo otro? ¿Seguir representando en el mundo nuestro personaje, seguir viviendo nuestro ensueño ancestral, o queremos mirarnos, conocernos, disolver este ensueño en la luz del conocimiento, bien que amoroso? (Zambrano, España, 16).

Al decir de Zambrano, si Unamuno presenta el cristianismo de don Quijote como una forma de revelación poética de la pasión trágica del ser, Ortega, por el contrario, se propone disolver esa figura casi mitológica, aclarar el ensueño de que es portadora y descifrar su enigma para extraer un proyecto, una ética (Zambrano, España, 34-35).

Anoto en este punto como resonancia el intento de don Quijote por salvar a un muchacho del maltrato de su amo, desatinadamente confiando en que el golpeador respetará su palabra a partir de una premisa ética del humanismo renacentista y en contra de la moral de casta:

—Mire vuestra merced, lo que dice — dijo el muchacho—, que 
este mi amo no es caballero, ni ha recebido orden de caballería alguna, que es Juan Haldudo el rico, el vecino del Quintanar.

- Importa poco eso — respondió don Quijote-, que Haldudos puede haber caballeros; cuanto más, que cada uno es hijo de sus obras (Cervantes, Don Quijote de la Mancha, I, 4, 65). ${ }^{2}$

\section{Una pregunta por la realidad}

En su "Meditación preliminar", el filósofo establece como necesidad humana la interpretación o la pregunta por el sentido de las cosas (Ortega y Gasset, Meditaciones del Quijote, 160). ${ }^{3}$ En relación con esta pregunta, y antes de referirse a la posibilidad de la perspectiva, Ortega establece, a partir de la imagen del bosque, una dicotomía entre lo patente y lo latente. Si lo patente acontece al salir a la superficie lo que es profundo, esto es, lo latente mismo, esto último se manifiesta activamente en la fuga de los ojos ante el bosque. "El bosque está siempre un poco más allá de donde nosotros estamos. De donde nosotros estamos acaba de marcharse y queda sólo su huella, aún fresca" (102).

Siguiendo a García Lara, en relación con la dimensión ontológica de la verdad, tanto Ortega como Freud parten de una visión de la realidad del mundo constituido como una superficie de datos y fenómenos sensibles. Estos datos adquieren profundidad a partir de la actividad organizadora del sujeto en la que encuentran su sentido (García Lara, Ortega y el psicoanálisis, 213).

El ser del bosque se constituye con la participación del sujeto frente a una porción de lo real, pues es éste quien, al inter-

${ }^{2}$ En las referencias al Quijote, incluyo la parte seguida del capítulo y la página.

3 “"...] el hombre tiene una misión de claridad sobre la tierra. Esta misión no le ha sido revelada por un Dios ni le es impuesta desde fuera por nadie ni por nada. La lleva dentro de sí, es la raíz misma de su constitución" (Ortega y Gasset, Meditaciones del Quijote, 160).

4 "El bosque huye de los ojos" (Ortega y Gasset, Meditaciones del Quijote, 160). 
pretar los sonidos que escucha, los distingue, ubicándolos en la cercanía o en la distancia. Será entonces la perspectiva lo que permita la construcción de una realidad: "Toda esta profundidad de lontananza existe en virtud de mi colaboración, nace de una estructura de relaciones que mi mente interpone entre unas sensaciones y otras" (Ortega y Gasset, Meditaciones del Quijote, 108). De esta manera, la actividad del sujeto transforma las cosas, sacándolas de su aislamiento y su mutismo. ${ }^{5}$

A partir de la distinción que establece entre la patencia y la latencia, Ortega hablará de la aparición de la verdad como "iluminación subitánea" (109) susceptible de transmitirse tan sólo en la práctica de una pedagogía de la alusión, "única pedagogía delicada y fecunda":

Por esto su nombre griego, alétheia —significó originariamente lo mismo que después la palabra apocalipsis - es decir, descubrimiento, revelación, propiamente desvelación, quitar un velo cubridor (Ortega y Gasset, Meditaciones del Quijote, 109).

Por su parte, el psicoanálisis sitúa la verdad psíquica en la latencia. La búsqueda de la verdad del sujeto alienado consiste en la producción de un saber sobre el objeto que causa su deseo, verdad particular que surge como alétheia, esto es, como desvelamiento del objeto en cuestión (García Lara, Ortega y el psicoanálisis, 129-130).

Ortega da cuenta del paso de la experiencia ontológica del mundo al conocimiento del mismo, lo que implica una construcción subjetiva que origina el mundo de la cultura. Ante todo, el filósofo parte de la experiencia de las sensaciones: "un

\footnotetext{
${ }^{5}$ García Lara establece una analogía entre el saber como producto del ejercicio del significante del que habla Lacan y el saber construido por el encadenamiento de elementos discretos organizados en estructura y por la organización de distintas perspectivas como unidad mínima del conocimiento que plantea Ortega (García Lara, Ortega y el psicoanálisis, 211).
} 
primer plano de realidades el cual se impone a mí de manera violenta, son los colores, el placer y dolor sensibles" (Ortega y Gasset, Meditaciones del Quijote, 114). A la herida de esas realidades primarias se contraponen otros planos de relación con el mundo que aparecen como queridos, esto es, sustentados en la voluntad: "La ciencia, el arte, la justicia, la cortesía, la religión son órbitas de realidad que no invaden bárbaramente nuestra persona como hace el hambre o el frío; sólo existen para quien tiene voluntad de ellas" $(1987,115)$.

Y si el ver qué resulta de la mera exposición a las impresiones primeras se reduce a un caos de puntos luminosos, una suerte de ceguera, el ver activo "que interpreta viendo y ve interpretando" es un ver que es mirar (115). La mirada se traduce en el escorzo, "órgano de la profundidad visual" (116), donde la simple visión se funde con un acto puramente intelectual. El Quijote, afirmará el filósofo, es el libro-escorzo por excelencia (119), en la medida en que se construye relatando paródicamente su forma de constitución. Ortega hablará después de un leer pensativo, el tipo de lectura que pide un libro como el Quijote que a su vez entraña, en las interpretaciones quijotescas del mundo, el reverso complementario de esta intelección.

Para establecer el contrapunto arriba referido, concluyo la sección con una resonancia quijotesca:

- Has de saber, Sancho, que este barco que aquí está, derechamente y sin poder ser otra cosa en contrario, me está llamando y convidando a que entre en él y vaya en él a dar socorro a algún caballero o a otra necesitada y principal persona, que debe de estar puesta en alguna grande cuita. Porque éste es el estilo de las historias caballerescas y de los encantadores que en ellas se entremeten y platican... (Cervantes, Don Quijote de la Mancha, II, 29, 868). 


\section{La herida de los sentidos}

En la misma "Meditación preliminar", Ortega se refiere al impresionismo de los pueblos del Mediterráneo, receptivos a lo que impacta los sentidos. De este modo, contrariamente al arte griego, gobernado y corregido por el pensamiento, la sensualidad meditarránea "rompe las cadenas de esclavo de la idea" (Ortega y Gasset, Meditaciones del Quijote, 136). ${ }^{6}$ Ortega destaca la importancia de la potencia de visualidad cervantina, capaz de convocar, entre la narración, impresiones de lo primero: colores, sonidos, cuerpos, las sensaciones vivas de las cosas (138). De esta manera, el arte mediterráneo "palpa con la pupila la piel de las cosas" (138). Ahora bien, esto último no implica, aclara el filósofo, un realismo, porque esta estética no consiste en la acentuación, sino en la apariencia de las cosas. De esta forma, la realidad:

- la fiera, la pantera - cae sobre nosotros de una manera violenta, penetrándonos por las brechas de los sentidos mientras la idealidad sólo se entrega a nuestro esfuerzo. Y andamos en pe-

${ }^{6}$ Presidido por el pensamiento de Zenón de Elea, el poema El cementerio marino (1922) de Paul Valéry se abre sin embargo a los delirios de la mar; palpa la piel de pantera y el cintilar de la clámide calada; se anega en la ebriedad azul de la carne oceánica; en la refulgencia absoluta de la hidra.

Oui! Grande mer de délires douée,

Peau de panthère et chlamyde trouée

De mille et mille idoles du soleil,

Hydre absolue, ivre de ta chair bleue,

Qui te remords l'etincelante queue

Dans un tumulte au silence pareil!

Paul Valéry, El cementerio marino, XXIII

[Sí, mar, gran mar de delirios dotado,

Piel de pantera y clámide calada

Por tantos, tantos ídolos del sol,

Ebria de carne azul, hidra absoluta,

Que te muerdes la cola refulgente

En un tumulto análogo al silencio.] 
ligro de que esa invasión de lo externo nos desaloje de nosotros mismos, vacíe nuestra intimidad, y exentos de ella quedemos transformados en postigos del camino real por donde va y viene el tropel de las cosas (Meditaciones del Quijote, 140).

Esta invasión de lo externo me remite a la novela cervantina, por donde cabalga don Quijote, testimonio del transitar del alma a cielo abierto, sin defensa alguna ante los espejismos y el cintilar de las imágenes. ${ }^{7}$ Ahora bien, la posibilidad de estar en el mundo provistos de una piel o filtro que nos permita establecer una distinción entre nuestra interioridad y lo que ocurre afuera implica la capacidad de amortiguar la irrupción; sólo así es posible, al decir de Ortega, "filiar" la impresión o, también en sus palabras, "someterla a civilidad", "pensarla" para asimilarla al edificio de la personalidad (140).

De esta manera, a la exposición a la luz calcinante de las apariencias ha de suceder el recubrimiento de la herida, curación operada por una forma de energía o aquietamiento que Freud denomina "ligada" (Freud, Más allá del principio del placer, 26). En este punto encuentro la figura del bálsamo de Fierabrás, carnavalización de la sustancia con que fuera embalsamado el cuerpo de Jesucristo, que habla de la restitución, de la incesante posibilidad de reparación presente en la fantasía quijotesca:

—Es un bálsamo — respondió don Quijote — de quien tengo la receta en la memoria, con el cual no hay que tener temor a la muerte, ni hay pensar morir de ferida alguna. Y ansí, cuando yo le haga y te le dé, no tienes más que hacer sino que, cuando vieres que en alguna batalla me han partido por medio del cuerpo, como muchas veces suele acontecer, bonitamente la parte del cuerpo que hubiere caído en el suelo, y con mucha sotileza, antes que la

7 "En Don Quijote se muestra la vida humana exenta de los elementos que normalmente la encubren...", afirma Marías en la introducción a la Meditaciones (Marías, "El primer libro de Ortega" en Ortega y Gasset, Meditaciones del Quijote, 28). 
sangre se yele, la pondrás sobre la otra mitad que quedare en la silla, advirtiendo de encajallo igualmente y al justo. Luego me darás a beber solos dos tragos del bálsamo que he dicho, y vérsame quedar más sano que una manzana (Cervantes, Don Quijote de la Mancha, I, 10, 114).

Este bálsamo remite a la plasticidad de nuestro sistema psíquico que, tal como lo explica el propio Freud en sus "Notas sobre la 'pizarra mágica'", es susceptible de transformarse en un sistema de escrituras o retranscripciones donde quedan inscritas las huellas de lo que nos impresiona, y donde brota la escritura literaria abriendo cauces de ríos subterráneos, excavando pasadizos con la persistente ceguera de los topos, descifrando huellas en los suelos arcillosos y que de este modo construye una forma de conocer que, oculta para ella misma, no sabe de sí sino en la medida de su lento despliegue.

\section{El concepto}

Para dar cuenta de la constitución de la realidad humana, en la misma "Meditación preliminar" el filósofo se refiere al concepto que, en sus palabras, constituye un órgano que capta la profundidad del mundo. Arriba apunté cómo, para Ortega, la profundidad tiene que ver con la latencia que, tal como lo explica a su vez Julián Marías, constituye un principio estructural tanto de la realidad como del conocimiento.

La estructura resulta de la vinculación de las cosas entre sí (Ortega y Gasset, Meditaciones del Quijote, 142n): "Una estructura es una cosa de segundo grado, quiero decir, un conjunto de cosas o simples elementos materiales, más un orden en que estos elementos se hallan dispuestos" (140). El sentido, agrega el autor, es la forma suprema de coexistencia de cada cosa con las demás.

Ahora bien, inmediatamente después de hablar de la estructura como vínculo entre las cosas, Ortega y Gasset lo hará so- 
bre el eros como principio dinámico de la máxima estructura: la "Naturaleza".

Diríase que cada cosa es fecundada por las demás, diríase que se desean como machos y hembras, diríase que se aman y aspiran a maridarse, a juntarse en sociedades, en organismos, en edificios, en mundos. Eso que llamamos "Naturaleza" no es sino la máxima estructura en que todos los elementos materiales han entrado. Y es obra de amor naturaleza, porque significa generación, engendro de las unas cosas en las otras, nacer la una de la otra donde estaba premeditada, preformada, virtualmente inclusa (Ortega y Gasset, Meditaciones del Quijote, 143).

De esta manera, el conocimiento implicará de manera central un impulso amoroso. La pregunta por el sentido de las cosas es la posibilidad de encontrar en un objeto el centro del universo, un lugar donde se anuden los hilos cuya trama es nuestra vida, nuestro mundo. Si al inicio de la "Meditación preliminar" se advierte la imagen de un cenobiarca erotizado, al final de la misma el filósofo declara que la meditación es un ejercicio erótico y el concepto, rito amoroso (144). Por su parte, García Lara intenta pensar esta forma de erotismo desde el psicoanálisis, donde el amor surgido de la transferencia se transformará en deseo de saber, "distinción que sitúa plenamente del lado de la actividad simbólica el impulso amoroso hacia el ser de las cosas" (García Lara, Ortega y el psicoanálisis, 137).

Adelante el filósofo establecerá una distinción entre la impresión de una cosa, lo que nos pone en contacto con su condición material, y el concepto, "que contiene todo aquello que esa cosa es en relación con los demás" (Ortega y Gasset, Meditaciones del Quijote, 145). De aquí se desprende la noción de concepto como límite, como algo virtual que marca y establece los confines de las cosas, para que convivan sin confundirse ni aniquilarse (147). Se trata de la "repetición o reproducción de las cosas mismas, vaciadas en una materia espectral" (149). El 
concepto, dirá el autor más adelante, es literalmente un órgano con el que captamos las cosas.

Me permito aquí apuntar una resonancia que surge de la noción de concepto, aunque tiene que ver, en realidad, con un fenómeno que ocurre al producirse una falla en éste. Si pensamos en don Quijote, al impacto de las cosas que se le vienen encima en forma de golpes o caídas o a la captación de éstas como un todo ininterrumpido o ilimitado o configurado por impresiones huidizas, sucede el intento de construir un mundo recurriendo a Dulcinea, que aparece como instancia intercesora a partir de la cual podrá desprender, si bien desgajado del concepto, una razón poética particular, una pauta para comprender el mundo.

\section{El espejismo y el sustrato de las cosas: la novela realista}

Para explicar sus ideas sobre la novela en la "Meditación primera", Ortega parte de una impresión de los sentidos:

En verano vuelca el sol torrentes de fuego sobre la Mancha, y a menudo la tierra ardiente produce el fenómeno del espejismo. El agua que vemos no es agua real, pero algo de real hay en ella: su fuente. Y esta fuente amarga, que mana el agua del espejismo, es la sequedad desesperada de la tierra (Ortega y Gasset, Meditaciones del Quijote, 216).

Fenómeno éste, seguimos a Ortega, que puede vivirse de manera ingenua y literal o bien de manera irónica. Ortega asociará la novela de aventuras, el cuento y la épica con la perspectiva ingenua y la novela realista con la perspectiva irónica u oblicua. En ésta última, lo poético consiste en el gesto o movimiento con el que lo ideal es reincorporado a la realidad (217). De esta manera, la novela realista procede revirtiendo la operación de la novela de imaginación y, en esta inversión, da cuenta de su 
propio proceso generativo, en la medida en que va derrocando las "máquinas mal fundadas" de la fantasía. ${ }^{8}$

Siguiendo la impresionante imagen de Ortega arriba citada, la novela realista parte de lo que falta, de la falla, la carencia, la imperfección, el sufrimiento y después confronta la fantasía que brota ante ésta con la implacable realidad, esa "cosa inerte y áspera" que se hace presente, "afirmando su muda, terrible materialidad frente a todos los fantasmas" (220).

García Lara aventura que la "realidad" de la que habla Ortega tiene que ver con lo Real lacaniano:

Habría que interpretar esta realidad a la que se refiere Ortega. Es evidente que la idea de lo Real desde la que he acercado la concepción psicoanálitica de lo imposible de decir, de lo inefable, no se corresponde a la idea de la realidad, en tanto que sería impensable una realidad humana fuera del lenguaje [...]. Así, pues, he de arriesgar la idea de que la realidad que menciona aquí Ortega, es una realidad que cae del lado de lo real, del lado del objeto, heterogéneo al sujeto del significante (García Lara, Ortega y el psicoanálisis, 152).

Se trata pues de la materialidad inefable del mundo; a la vez caótica y absoluta; originaria, sin fisuras. Lo real aparece como la potencia destructiva de la circunstancia, el "lado moridor" de la realidad, como lo expresaría el novelista mexicano José Revueltas. Ortega desprenderá de esta incorporación de lo que llama "materialidad" a la novela su noción de realismo.

He ahí lo que llamamos realismo: traer las cosas a una distancia, ponerlas bajo una luz, inclinarlas de modo que se acentúe la vertiente de ellas que baja hacia la pura materialidad (Meditaciones del Quijote, 222).

8 "En efecto, llevad la mira puesta a derribar la máquina mal fundada destos caballerescos libros, aborrecidos de tantos y alabados de muchos más, que, si esto alcanzásedes, no habríades alcanzado poco." (Cervantes, Don Quijote de la Mancha, Prólogo, 18). 


\section{La novela realista y el héroe}

En su comentario al episodio del retablo de Maese Pedro, Ortega establece dos espacios: por una parte, el ámbito de la aventura; por la otra, el de la realidad. La profundidad o escorzo del episodio radica en la conjugación de la realidad actual y del mundo imaginario épico. "Don Quijote es la arista en que ambos mundos se cortan formando un bisel" (212). Efectivamente, el protagonista se sitúa en el umbral entre la realidad y la ficción:

Y en diciendo y haciendo, desenvainó la espada y de un brinco se puso junto al retablo, y con acelerada y nunca vista furia comenzó a llover cuchilladas sobre la titerera morisma, derribando a unos, descabezando a otros, destropeando a éste, destrozando a aquél... (Cervantes, Don Quijote de la Mancha, II, $26,850)$.

La novela, dirá Ortega, es una de las formas de interpretación del hombre (Ortega y Gasset, Meditaciones del Quijote, 183); surge en las antípodas del mito y de la épica, de un afán de imitar que tiene origen en la comedia. La novela cervantina trata de un personaje que, en su afán de aventura, se quiere épico, en otras palabras, de un sujeto que afirma su sustrato en un más allá de sí mismo. ${ }^{9} \mathrm{Y}$ es que si las aventuras son "vahos de un cerebro en fermentación", la voluntad de aventura, en cambio, "es verdadera" (226). Se trata de un afán, de un proyecto que pretende gobernar y componer la dura realidad, de una forma de heroicidad que se identifica con la noción de autenticidad heideggeriana. ${ }^{10} \mathrm{~A}$ su vez el psicoanálisis presenta al hombre

9 "La aventura quiebra como un cristal la opresora, insistente realidad" (Ortega y Gasset, Meditaciones, 207).

10 "Porque ser héroe consiste en ser uno, uno mismo" (Ortega y Gasset, Meditaciones del Quijote, 227). 
como un ser deseante. De esta manera, el Heidegger de Ser y tiempo resulta referente común de Ortega y el pensamiento psicoanálitico, en la medida en que habla de la angustia y de la cura en relación con la historicidad y la muerte.

Ante la disposición heroica, Ortega establece la posibilidad de dos perspectivas: la trágica y la cómica (230). El sujeto trágico no es el hombre de carne y hueso, sino el ser "en cuanto que quiere", esto es, en tanto que proyecto de sí (232). La vida del héroe consiste en una incesante resistencia a la tradición, a lo recibido, con la pretensión de que, paradójicamente, "una idea, un corpúsculo, menos que aéreo, súbitamente aparecido en la fantasía", haga estallar lo que al sujeto se le impone (237). Se trata de un "querer" creador de un nuevo ámbito de realidades.

En cuanto a la perspectiva cómica, se trata de la vertiente que conduce al héroe hacia la pura materialidad (238); fuerza que, resistente al impulso del personaje, descarga directamente sobre el cuerpo, precipitando su caída.

El antepenúltimo apartado de la misma meditación se refiere a la novela como género tragicómico; en el doble registro del género se funda la consideración de que la novela realista presenta una perspectiva más compleja que la de la mera materialidad, y que su carácter poético tiene que ver con el hálito, aliento o latido que se ve fuertemente atraido por el vórtice de lo real, pero en el que éste encuentra también resistencia. ${ }^{11}$

\footnotetext{
11 "Cuando se ha insistido sobre el realismo de la novela debiera haberse notado que en dicho realismo algo más que realidad se encerraba, algo que permitía a ésta alcanzar un vigor de poetización que le es tan ajeno. Entonces se hubiera patentizado que no está en la realidad yaciente lo poético del realismo, sino en la fuerza atractiva que ejerce sobre los aerolitos ideales" (Ortega y Gasset, Meditaciones del Quijote, 240).
} 


\section{A manera de conclusión}

En sus Meditaciones del Quijote, Ortega y Gasset parte de la necesidad de humanizar la circunstancia y termina hablando de la caída de ese impulso heroico tal como ocurre en la novela. Al hacerlo, apunta una diferencia entre el discurso filosófico y el discurso literario.

En este contexto, intentaré anotar algo sobre la importante formulación que aparece en el prólogo "Lector...": "Yo soy yo y mi circunstancia, y si no la salvo a ella no me salvo yo" (Meditaciones del Quijote, 77). En este enunciado, aparece un yo que se capta en la intimidad de su decir y que, al mismo tiempo, se mira proyectado en el mundo como existente, en la alteridad de una enunciación en la que se pierde de vista. De ahí la necesidad de salvar esa otredad que es la circunstancia en que se implica: "Hemos de buscar a nuestra circunstancia, tal y como ella es, precisamente en lo que tiene de limitación, de peculiaridad, el lugar acertado en la inmensa perspectiva del mundo" (75). Siguiendo a García Lara, en esto consiste la "escritura filosófica orteguiana” (García Lara, Ortega y el psicoanálisis, 217).

De esta manera, si la cultura es el proceso de absorción de las circunstancias por el hombre, ${ }^{12}$ la novela realista da cuenta del proceso contrario:

Cervantes reconoce que la cultura es todo eso, pero, $;$ ay! es una ficción. Envolviendo a la cultura - como la venta al retablo de la fantasía - yace la bárbara, brutal, muda, insignificante realidad de las cosas (Ortega y Gasset, Meditaciones del Quijote, 222).

Ahora bien, someterse al enfrentamiento de las circunstancias implacables nos remite, sin embargo, a esas realidades

12 "Ser hombre es tener que reabsorber la circunstancia, humanizarla, incorporarla a su proyecto" (Ortega y Gasset, Meditaciones del Quijote, 162). 
primeras a partir de las cuales se construye el mundo y, por tanto, a la permanente posibilidad de que las cosas sean de otra manera. Así, la dimensión tragicómica de la novela cervantina aporta elementos importantes para destronar la idolatría de la razón abstracta y abre caminos para pensar otras razones. 


\section{REFERENCIAS}

Cervantes, Miguel de, Don Quijote de la Mancha, Edición del Instituto Cervantes dirigida por Francisco Rico, Barcelona, Instituto Cervantes-Crítica, 1999.

Freud, Sigmund, Más allá del principio del placer [1920], en Obras completas XVIII, trad. José L. Etcheverry, Buenos Aires, Amorrortu, 1999a.

__, "Nota sobre la "pizarra mágica"” [1924], en Obras completas XIX, trad. José L. Etcheverry, Buenos Aires, Amorrortu, 1999b.

García Lara, Carlos Enrique, Ortega y el psicoanálisis. El yo necesario y la ética del deseo, Alicante, Universidad de Alicante, 1997.

LaCAn, Jacques, Seminario 2 [1954-1955], texto establecido por Jacques-Alain Miller, Buenos Aires, Paidós, 6a. ed., reimpresión, 2006.

—_ Seminario 6 [1958-1959] (transcripción de una versión estenográfica).

Ortega y Gasset, José, El Quijote en la escuela [1920] en Obras completas, t. II, Madrid, Revista de Occidente, 5a. ed., 1961a.

__, "Vitalidad, Alma, Espíritu" [1924], en Obras completas, t. II, Madrid, Revista de Occidente, 5a. ed., 1961b.

__, La deshumanización del arte e ideas sobre la novela [1925], en Obras completas, t. III, Madrid, Revista de Occidente, 5a. ed., 1962.

—_, Meditaciones del Quijote [1914], Julián Marías (ed.), México, Cátedra-REI, 1987.

__ "Psicoanálisis, ciencia problemática" [1911], en Obras Completas, t. I, Madrid, Alianza, 1a. reed., 1988.

__ "Prólogo" a las Obras completas de Freud [1922], en Obras completas, t. VI, Madrid, Alianza, 1a. reed., 1989.

SAfouan, Moustapha, Lacaniana. Los seminarios de Jacques Lacan 1953-1963 [2003], trad. Nora González, Argentina, Paidós, 1a. reimp., 2005.

VALÉRY, Paul, El cementerio marino [1922], trad. Jorge Guillén, Madrid, Alianza, 1995 (El libro de bolsillo, 86).

Zambrano, María, España, sueño y verdad [1965], Madrid, Siruela, 1994. 
